\title{
Exploring the notion of presen-
}

in remote collaborative learning environments

\section{ABSTRACT}

In this paper we discuss issues related to communication and social dynamics characterizing remote collaboration between distant communities. These observations emerge from ethno-graphic researches conducted in collaborative workshop involving MIT-Massachusetts Institute of Technology students with other universities or private companies. The focus of the paper is the notion of presence. This notion is analyzed through three different related aspects: the presence of information, the presence of communication tools and, finally, the presence of people. These analysis give indications on how better design space for learning and remote collaboration using interactive multimedia communication tools.

\section{RESUMO}

Este texto discute questões relacionadas com comunicação e dinâmica social e que caracterizam colaboração à distância entre comunidades. As observações obtidas vieram de workshops conduzidos com estudantes do MIT, e outras pessoas de outras universidades e da iniciativa privada. $\mathrm{O}$ foco desta análise é a noção de presença sob três diferentes perspectivas: a presença da informação, a presença das ferramentas de comunicação e a presença de pessoas. Este estudo forneceu indicações de como melhorar o design de espaços para aprendizado e colaboração à distância usando ferramentas comunicacionais multimídias interativas.

\section{KEY WORDS (PALAVRAS-CHAVE)}

- Remote collaboration (Colaboração à distância)

- Learning environments (Ambientes de aprendizado)

- Communication dynamics (Dinâmica comunicacional)

- Collaborative media (Mídia colaborativa)

- Connected communities (Comunidades conectadas)

Federico Casalegno*

\section{Introduction}

New communication technologies radically change our relationship with knowledge, alter the access to information and the communication processes between people and cultures. New multimedia environments modify collaboration between communities and individuals, redesigning pedagogical methods and learning environments. Moreover, new collaboration forms further modify the way we access and process social knowledge, either in co-present in situ or in distant interaction presence mode.

Relationship between media, knowledge and communities is dynamically evolving. Within a scholastic environment, these new emerging paradigms regarding the transmission of knowledge are particularly evident. As Meyrowitz reminds us in [No sense of Place, 1985], places, knowledge and the stratification of social roles have always been interconnected. Social roles, the segmentation of knowledge into age groups, the access and use of information have been always interdependent. The author reminds us of the emblematic anecdote of a child who interrupted a lesson on the greatness of US presidents to say that President Nixon was defined as a rascal on television. In a pre-television environment, family, school and social context controlled information establishing "what information to give, to whom and when". Mass Media has completely upset this scenario, diffusing the same information to all age groups and social categories, redesigning the barriers between social spaces, knowledge and

MIT - Massachusetts Institute of Technology/USA 
the physical presence of the interlocutors. Nowadays, new collaborative multimedia environments stand for a higher leap towards this redefinition of accessing knowledge dynamics, opening the way for new ways of cooperating between communities and cultures.

We discuss hereafter some aspects that concern these emerging dynamics. These observations are the result of research I have been carried out mainly focusing on communication forms within remote collaborative learning environments These results are based upon empirical studies through ethnographic observations and semi-direct interviews during collaborative workshops between students from MIT - Massachusetts Institute of Technology and other universities (Miyagi University, Japan, IST Lisbon, Portugal) or with private companies (Forsters and partners, London).

These workshops took place in remote collaborative learning environments; in order to carry out common design projects students and teachers used a dedicated Web Site, chat-lines, Instant Messaging, email, as well as videoconferencing via Netmeeting or Picturetel. Moreover, they followed "common" lessons and worked in mixed teams. Their groups were made up so that they all were trans-universities partners, playing the role of consultants and critics when creating common projects ${ }^{1}$.

We are not going into details in the description of the workshops, design projects, media environments or communication technologies but we present some observations derived by the direct participation in these workshops.

\section{Presence of Information}

\subsection{The presence of the facilitator}

In complex environments like those shaping during remote collaborations, it is important to differentiate the availability of information and the participants' actual use of it. Even if this might sound rhetorical, it is necessary to stress that when designing collaboration environments, this element is not always taken into consideration.

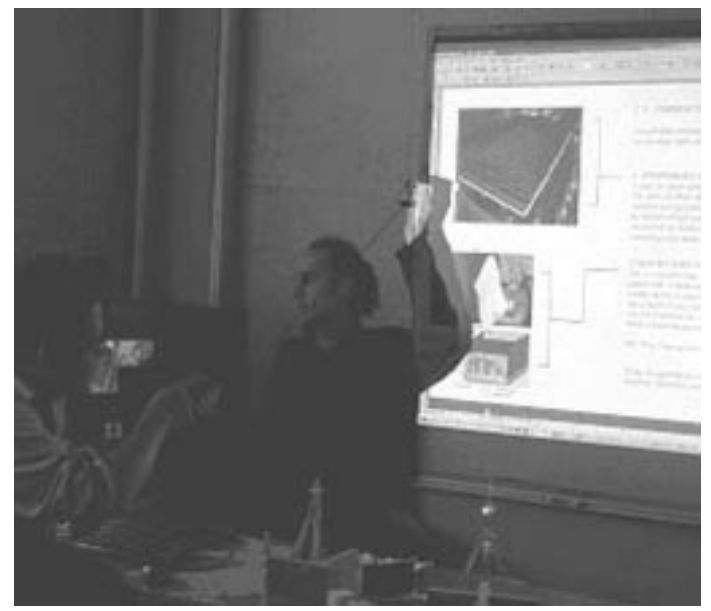

Fig. 1 - Using digital camera to indicate contents during remote interaction

Nowadays, thanks to the development of information networks, the opportunity to access data base, online information and to interact with distant communities is always more spread and concrete. In remote collaborative learning environments the facilitator plays a fundamental role in guiding participants to find, access and process the right information they need for the project at the right moment. During distant interactions there is always the need of the presence of a guide, a tutor that indicates the participants where, when and what file they can find and use for a specific purpose.

In fact, during the remote collaborative sessions, students had to put their files online to [a] create their own design project and $[b]$ share their files during cross presentations via videoconferences. Furthermore, they had to access other students' files with information concerning their project. Finally, they had to upload documents with programs and scripts to print 3D models. The presence and the role of the facilitator turned out to be fundamental in directing people to access the information: he played a role of cross-fertilization agent among dis- 
tant groups.

Secondly, in this context the crucial necessity of contextualizing information and knowledge arises; Edgar Morin (Morin, 1999) indicates the capacity to contextualize information as one of the seven fundamentals of knowledge for future education.

Considering communication dynamics in collaborative learning environments, the difficulty lies not in the technological setting, but lies in the connection between the set of necessary information for the design project in a given moment, the time of access it and process the knowledge that groups create along the project. The presence of a facilitator plays the important role in organizing the dynamics of information flows and knowledge management, even among very high computer literate communities.

\subsection{Presence of communal memory}

The fundamental thesis of the European Union project Living Memory ${ }^{2}$ assumed that connected community, to exist, needs a shared memory and, secondly, that connected involves communication and shared information.

In the same way, when dealing with instant communities like those emerging in remote collaborative learning environments, we need to create a collective memory as necessary condition for the good dynamics of collaboration between these distant communities. Without this collective memory, collaboration is very difficult to be efficient; therefore all the processes that favor the birth of it are extremely effective.

Collective memory is a complex process, but it is created when our personal memories and our information merge with other people's memories and information that we, and the others, have created. Memory, furthermore, is "responding" rather than "recording"; M. De Certeau (1982, p. 131 and following.) underlines that a memory lives when people appropriate it and secondly that it is regulated by the game of alteration. Memory exists only through the permanent and constant alteration by the members of the community. Moreover, collective memory draws its power of intervention from its own ability of being altered, moved.

Fig. 2 - Home page of Archnet, web based on-line collaborative platform

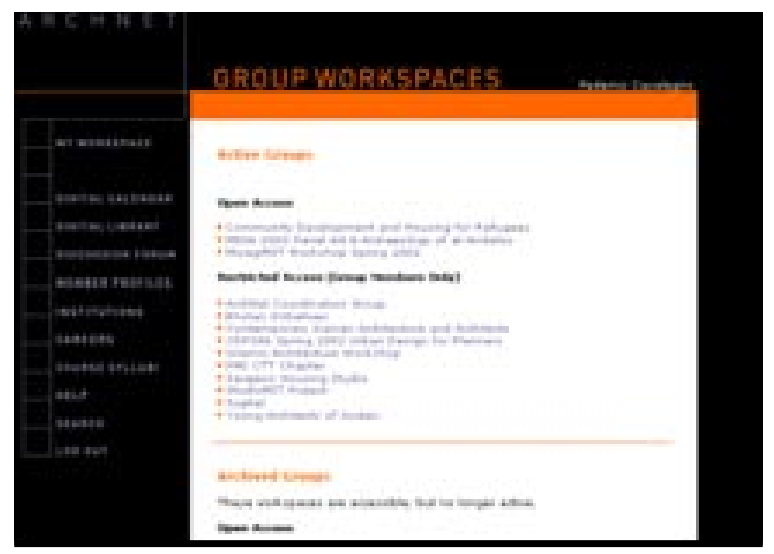

With these assumption in mind, the fundamental point in designing remote collaborative learning environments is the study of online spaces and communication dynamics that support and favor the creation of a common memory, allowing the members of the community to play an active role in its creation. Memory, does not emerge from a simple fruition and a mere access of impersonal information, yet it takes place through the active construction of information and knowledge created by community members themselves. People who are involved in collaborative workshops have to create their own common memory to have the feeling of "inhabiting" a space and belonging to the community. Edgar Morin (1977) underline that the environment is not only co-present for individuals, but it is also co-organizer. People and environment constitute an eco-dependant system that is mutually influenced. Enabling people to build their own environment, be it real or virtual, strengthens their feeling of belonging to a community. On this aspect, Martin Heidegger (1955) reminds us that 
"the feeling of living in a place", in its full and original meaning, becomes true in the act of building. Building has the objective of letting us inhabit a place, making us belong to that place, developing a sense of belonging. If this is true for physical space, it's also true for the architecture of cyberspace. Building, for Heidegger, not only is a means for inhabiting, but in itself is already a phenomenon of inhabiting. Showing how the verb "to be" and "to live" in German, have the same root (bauen, buan, beo), he shows how "to be" and "to live" share the same value. In these terms building is a form of inhabiting itself; the Archnet ${ }^{3}$ or StudioMIT ${ }^{4}$ website used during remote collaboration, have a high level customization tools that enable the learning community to create and find the most appropriate web platform for their purposes. The customization dynamics, creating discussions forums, shared file folder, mailing list, webcast lectures, video and data archives, allows an highly meaningful experience for the learning community.

Secondly, from a pedagogical point of view, the courses were designed in a way to ask students to post their work in progress weekly and discuss it together. Seymour Papert's notion of constructionism (Papert, 1992) emphasizes the importance of externalized, socially sharable entities, artifacts or objects in the learning process. The learning process is based on the internalization of the external information and by the externalization of internal information, in a cyclic perpetual shape.

Bearing this conceptual framework in mind, any process allowing the students to create their own space, to manipulate and customize it, increases their sense of belonging to a community. Moreover, sharing memories helps to the creation of the context: during the communication process, one of the first phases is to establish a body of common knowledge on which people agree, and this allows social actors to communicate and better cooperate.

The on-line web platform used during the remote collaboration became a dynami- cally constructed collective memory for the community, the presence of the collective knowledge created during the on-going work. It represents, at the same time, the mark of the presence of the collective knowledge and of the learning community.

\section{Presence of communications' to- ols}

Remote collaborative environments are based upon the diversity of the communication media used for the collaboration and communication processes.

The simultaneous use of communication technologies in synchronous and a-synchronous mode, allowing the access to information both locally and remotely, creates completely new knowledge environments. These processes create new dynamics because the synergic use of tools creates remarkably innovative behaviors as far as communication and education are concerned.

Bill Mitchell (1999) summarizes this new paradigm in the following scheme;

Moreover, at the MIT, as it is happening in a growing number of universities, wireless access to the cyberspace is creating

\begin{tabular}{|c|c|c|}
\hline CoAamenocatson & SYNCH & Asvivel \\
\hline LOCAL. & $\begin{array}{l}\text { Atelier, } \\
\text { Classroom }\end{array}$ & $\begin{array}{l}\text { On-site } \\
\text { collection }\end{array}$ \\
\hline REMEOTE & $\begin{array}{l}\text { Video- } \\
\text { conferencing }\end{array}$ & $\begin{array}{l}\text { Email } \\
\text { Web-pages }\end{array}$ \\
\hline
\end{tabular}

new educational setting. Students use their laptops in the classroom: it is always more frequent that a student interrupts a lesson to "add" new information to the lesson they are following in their class because they are using the access to the Internet to enrich the face-to-face lessons. These synergies between physical and electronic spaces are becoming more and more frequent.

New technologies allow for the realization of complex and innovative collaborative environments that strongly influence learning and teaching forms. Presence of informa- 
tion from the cyberspace and learning community physical co-presence are more and more complementary.

Fig. 3 - Students interacting and exchanging file via video-conferencing

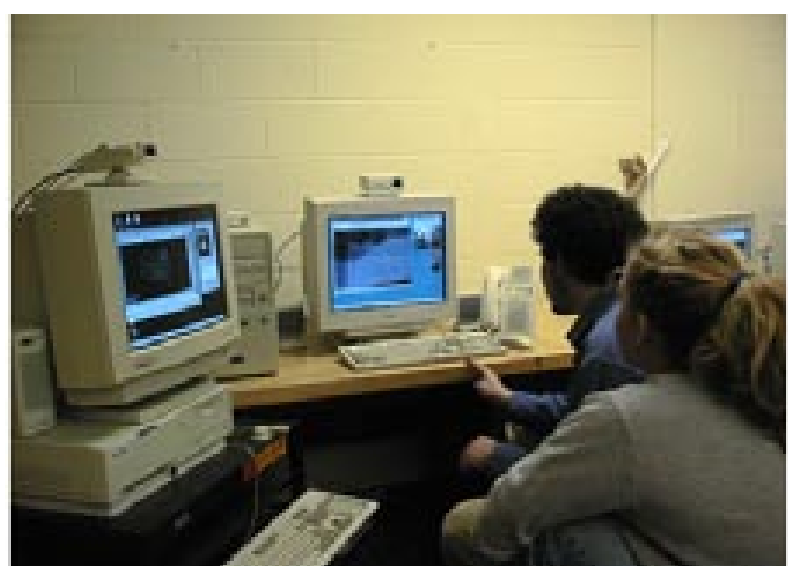

Secondly, we do not consider media as neutral. Media mediate communication. For that, we should take into consideration that every communication system has its peculiar features that can enhance certain elements of interpersonal communication presenting advantages or disadvantages. "Technology is therefore no mere means. Technology is a way of revealing. [... ] Thus what is decisive in techne does not lie at all in making and manipulating nor in the using of means, but rather in aforementioned revealing.

It is as revealing, and not as manufacturing, that techne is a bringing-forth (Heidegger, 1955, p. 12 and 13)". Technology, as the German philosopher reminds us, is a way of revealing and this is a fundamental characteristic.

On these aspects, we can emphasize that "face-to-face" interaction, in real time, with video images and audio messages, cannot be considered the best by far. Chat and emails for example, allow the users to develop their imagination if they do not see their partner during the interaction: they have the opportunity of imagining their correspondent, favoring imagination in dialogues and exchanges or giving more freedom to the message issuer that remains anonymous.

Voice or video image, giving more defined images of the person who is releasing information, can limit freedom and imagination that email allows by transmitting less information. Secondly, asynchronous communication via email allows us to better think before sending out information, allowing for a more effective exchange for the collaboration.

It also allows people from different cultures to better articulate and prepare their messages (for instance for those students that are not English mother tongue, this is undoubtedly an advantage when collaborating with English mother tongue students).

Thirdly, asynchronous communication allow for the creation of archives and consequently of a common memory that as we mentioned before, is fundamental in order to create a community and an affective collaborative process.

Another important final remark concerns the fact that during the workshop the participants used communication tools in a different way from what they normally do; the participants' habits were modified within a very short time. In this sense, students used media that they usually use, but with different aims and dynamics. This is why when designing collaborative environment it is important to pay attention to the information dynamics process and clearly point out the aims that people need to reach when using different communication tools.

When we design a remote collaborative environment it is important to link the media to the required action, thus creating a more explicit relationship between technology and finality during the cooperative process. In this sense the importance of establishing certain rhythms in communication, which otherwise remains fragmentary, emerges.

\section{Presence of people}

\subsection{Presence trough personal artifact and}




\section{trivial communication}

It is important to create occasions for meetings and preliminary exchanges at the beginning of the collaborative workshop: socialization and social ties strengthen collaboration forms. In fact, only thanks to socialization dynamics, during which the two remote teams managed to get to know each other via chat or voice conversations, the will of going really into the collaboration emerged.

Fig. 4 - Socialization phase via video conferencing

During some workshops, students

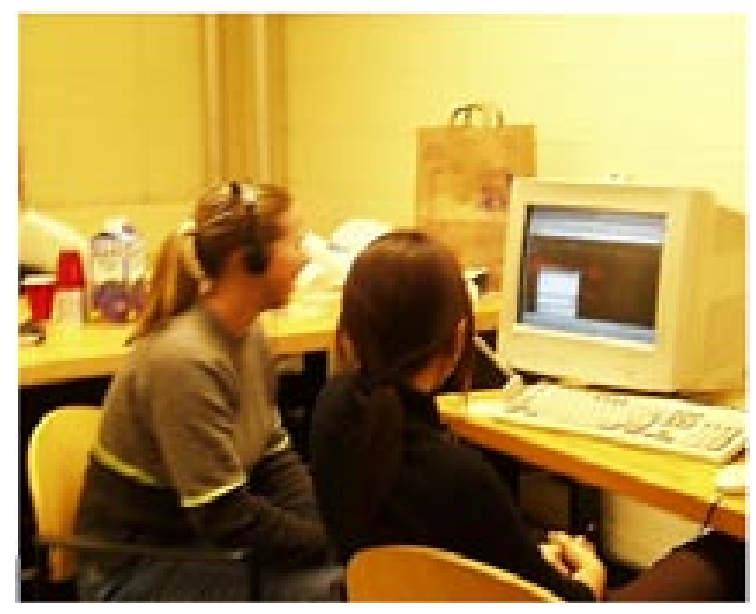

were asked to send short curricula and selfintroductions with pictures before starting the collaboration. In other cases, pages with the pictures and the names of the participants were created so that it was easier to visually recognize the presence of distant interlocutors and to connect "a name to a face". We can think of the difficulty that Western students can have recognizing and naming Asian students and vice versa. The time available to know each other is sometimes very short and therefore it is essential to find dynamics for socialization that are effective and rapid. In other cases, students created personal ad hoc web sites to introduce themselves and share their interests.

Furthermore, it is important to establish a sense of identity and of belonging to a community, putting the participants in the condition of giving and not only receiving information. That is why for instance, create personal artifacts to share, or sending out pictures before the workshop or creating audio files, having pictures with names, helps creating this community feeling within students.

Finally there is a correspondence between the quantity of time spent chatting about trivial issues and the quality of cooperation. In fact, the more the students chatted with each other freely about all kind of subjects rather than their design project, the more their collaboration turned out effective in the end (Phatic communication, $\mathrm{R}$. Jacobson, 1960, and trivial and tactical communication, M. Maffesoli, 1990).

This also shows how it is complex to give a structure to collaborative processes. During videoconferences among small teams, it was easy to notice that the communication between teams concerned more ordinary issues rather than their strictlyprojects oriented topics. Yet collaboration was possible thanks to these extra-curricula conversations.

Learning and collaboration is unpredictable and take place in some cases outside predetermined schemes; remote collaborative learning environments should try to support these dynamics.

\subsection{Visual Presence}

The video, as well as the mere visual presence of the different partners, is extremely important, even when the teams are not directly engaged into a collaboration phase or into active communication. Small Webcams were always active thus allowing for the creation of common environments and giving a sort of physical presence to the partners even when people were not directly communicating.

Secondly, we notice that video connections establish a contact between our environment and the external one. During the interaction we receive and send out visual messages concerning the environment: 
for example, visual information coming from the Miyagi Japanese University told us about their school structure, social arrangement, relationships between people, all of which clearly have a strong impact on people's communication.

Fig. 5 and 6 - using the video during the remote collaboration

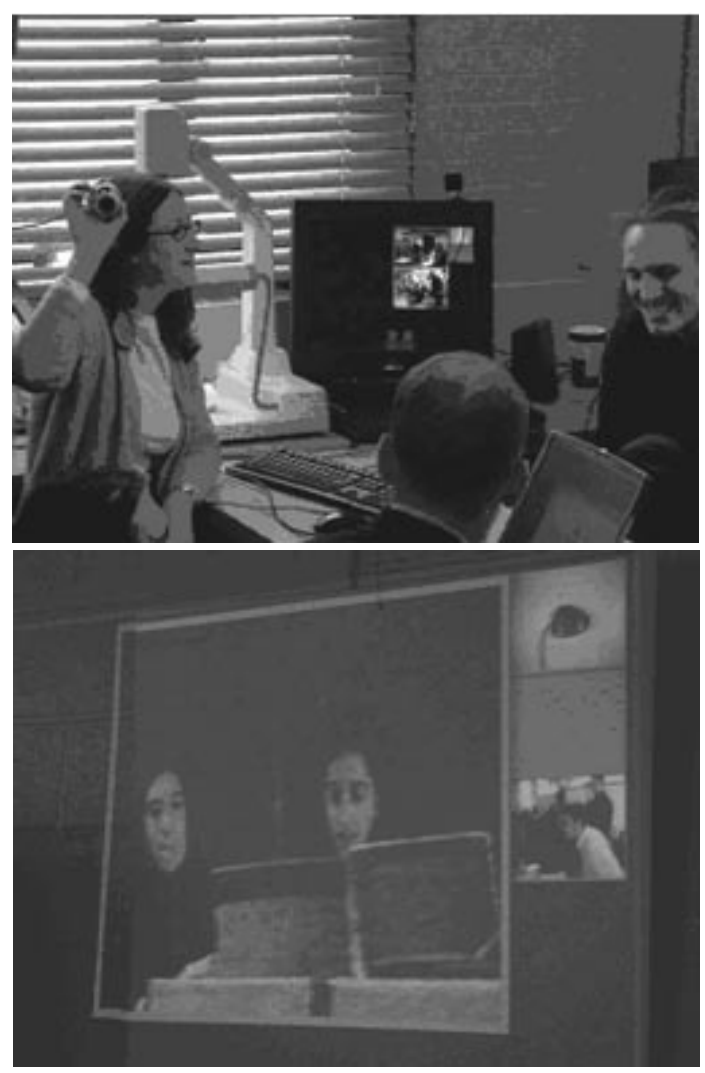

We can also observe that during the workshop, MIT students were allowed to eat and drink: if this can be seen in the US as a way of establishing an informal atmosphere, it is in contrast with the Japanese teammates, who think it is inappropriate to eat at their workplace, and it marked the cultural and behavioral differences between the two groups.

Moreover, MIT students used different classrooms while the Japanese students worked in the same classroom throughout the workshop. These information were transmitted by live images; MIT students think that their partners, being always in the same room, developed a stronger cohe- sion and consistency feeling, a sort of feeling of continuity and community.

We can consider that through video connections, we establish a visual connection through spaces which reflects into a whole new and yet much more complex communicational environment. This visual space gives the shared environment a certain consistency.

Thanks to the fact that the students are able to see each other, they feel that they are sharing the same physical and social environment.

\section{Presence of learning community}

Fig. 7 - Screen during remote collaboration. We can see video images of the 2 places, shared

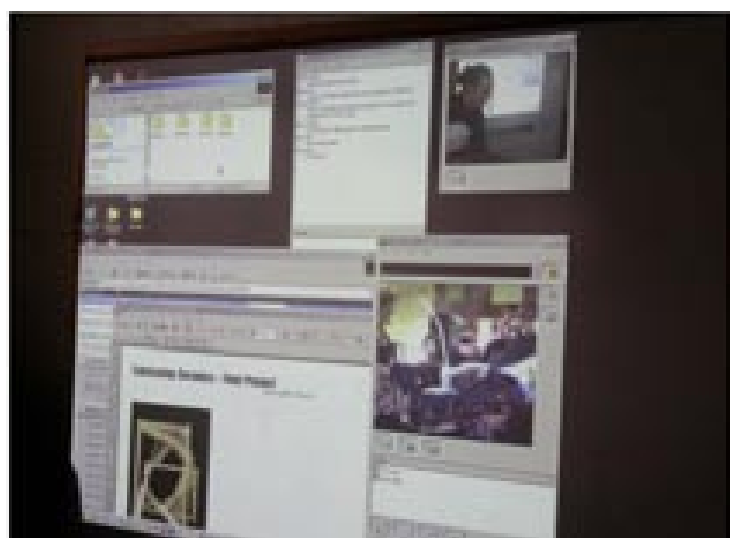

database, and share files

Fig. 8 - Media space during team-to-team work

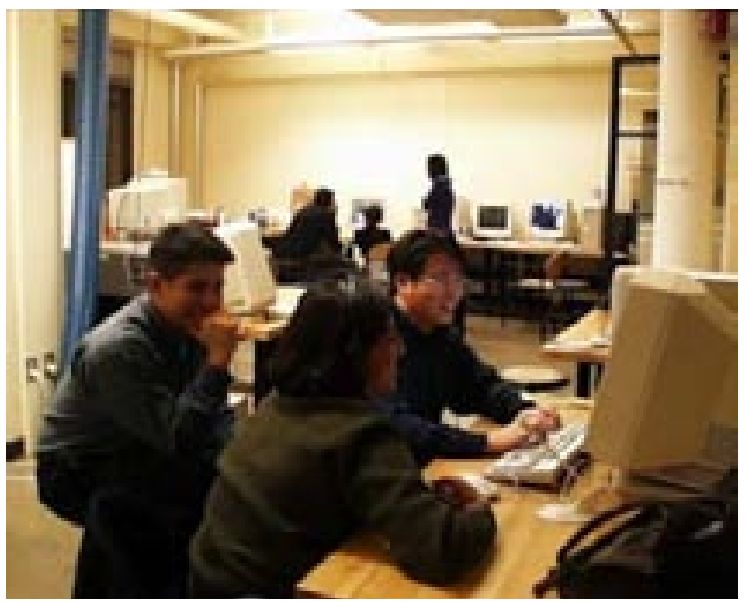

Learning and social interaction spaces, 
with the introduction of multimedia and interactive technologies on the one hand, and the opportunity to benefit from the remote presence of people on the other, are radically evolving. Creating a place that supports the learning community, encouraging interaction among community members and providing resources to allow fruitful interaction and creative thinking is the real challenge. With these aims, collaborative environments should aim to support interaction dynamics and create the context for these kind of interactions.

We need to transform a place into a space, as De Certeau (p. 173) emphasizes. He maintains that the space is to the place as "words when they are spoken"; that is the space is a lived place. A street is a place geometrically defined by city planners, but it is transformed into space by pedestrians. Remote collaborative environments are therefore places that turn into spaces depending on the use that you make of them.

On the other hand, we know that there are no such things as moments to "learn", "create" or "teach"; creative ideas come accidentally or in those moments when you do not expect it. Accidental learning is a fundamental aspect with which technologies confront themselves. Designing remote collaborative environments is a difficult task since you need to give a structure in an accurate and functional way to the environment but, on the other hand, you need to give freedom to those using them, without imprisoning learning or communication dynamics. If we think back to the difference that M. De Certeau makes between strategies and tactics (De Certeau, 1990, p.57), we can say that implementing places for remote collaboration you try to foresee strategies aimed at making communication effective and optimize the results. However, tactics made by students are often far from the main path, inventing creative and innovative solutions. The tension between foreseen strategies and used tactics is therefore a crucial point in collaboration.

These aspects are extremely relevant if we consider that we are heading towards a creative society, as Mitchel Resnick defines it (Resnick, M., 2002). The use of computational media and IT must not be reduced to the sole passive use of software, but on the contrary, users are active also when programming and creating software and technologies that are fit for their needs.

Remote collaborative learning environments must therefore manage to promote these dynamics and to support these processes, finding the right balance between the freedom of users and the rules imposed by technological implementation.

\section{Some conclusions}

Remote collaborative learning environments have the difficult role of bringing people together so that they can interact and cooperate. Therefore they need to favor different forms of presence in order to allow for the development of collective learning, creativity and collaborative forms.

As Martin Heidegger underlines, technology is not neutral. When designing remote collaborative learning environments is therefore necessary to take into consideration the peculiarities of the different communication tools in order to better benefit from their relative advantages. New interactive environments mediate communication and filter interactions, amplify and reduce socializing, communication and presence forms.

Moreover using different complementary tools creates innovative synergies as far as distant forms of presence and collaboration forms are concerned. They create new forms of presence, both in local remote collaboration and in situ interaction in virtual environments. Nowadays we are facing the challenge of finding most effective dynamics to favor the birth of learning communities.

Finally, it is very important to reconsider the role of collaborative environments; they do not come before social relations, but 
they support them. Michel Maffesoli insisted on the primordial role of social relations over the technological infrastructure, primum relationis. Thus, within the dialectics of technological networks and social/communication nets, we can stress how technology can amplify interpersonal relations without preceding them.

Furthermore, presence does not mean that we allow for an increasingly intense exchange of information or provoke situations of permanent contact and constant communication between distant places.

Remote collaborative learning environments must consider the need for this silent space of dialogue, where information can take shape, sediment and take on a meaning for interlocutors and communities. And this is a matter of communication dynamics rather then technological issues; these spaces could be technological, but they could also crystallize outside the technology sphere.

In some cases the visual background, the simple visual presence of another person, without necessarily promoting an active and targeted exchange of information, can be decisive and add meaning to the presence of distant partners.

The relationship between media, information, space and communities is rapidly changing and there are new emerging paradigms shaping the notion of presence.

\section{Notes}

* $\quad$ Federico Casalegno, Ph.D.

MIT Media Lab/ federico@media.mit.edu

http:// web.media.mit.edu/ federico

1 For more information of the tools used, please visit http://web.media.mit.edu/ federico/creativity/ All URL mentioned on this paper has been accessed on May 242004.

2 __ http://www.memoire-vivante.org

3 http://www.archnet.org

4 http://studio.mit.edu

\section{References}

BASTIDE, Roger, "Mémoire collective et sociologie du bricolage", L'Année sociologique, $\mathrm{N}^{\circ} 21,1970$.

DE CERTEAU, Michel, L'invention du quotidien. Arts de faire, Éditions Gallimard, Paris, 1990

DE KERCKHOVE, Derrick, Connected Intelligence: The Arrival of the Web Society, Somerville House Books; June 1997.

HEIDEGGER, Martin, The question concerning technology and other essays, Harper and Row, 1977 (1955).

JAKOBSON, Roman,"Closing statement; Linguistics and Poetics", in Style in Language, edited by Thomas A. Sebeok, MIT - Press editor, 1960.

LÉVY, Pierre, The collective intelligence. Mankind's emerging world in cyberspace, Plenum Trade, New York, 1997 (15t ed, 1994).

MAFFESOLI, Michel, Aux creux des apparences. Pour une éthique de l'esthétique Paris, Plon, 1990.

MALINOWSKI, B., "The problem of meaning in primitive languages", in The Meaning of Meaning, C. K. Ogden and I. A. Richards,Eds.: Harvest Book, USA, 1989 (1923).

MEYROWITZ, Joshua, No sense of place, New York, Oxford University Press, 1985.

MITCHELL, William J., E-Topia, MIT Press, Cambridge, USA,1999.

Beyond productivity. Innovation technology, Innovation and creativity. The National Academic Press, Washington, D.C. 2003.

MORIN Edgar, Les sept saviors nécessaires à l éducation du futur, Ed. Du Seuil, Paris, 1999.

.La méthode. La nature de la nature. Tome 1, Ed. Du Seuil, Paris,1977.

RESNICK, Mitchell, "Rethinking learning at the digital age". In Global Information Technology Readiness Report 2001-2002, edited by G. Kirkman, University Press, 2002, USA. 